\title{
Presumptive Q-scalar Implicatures
}

\author{
Lirong Bai \\ School of Foreign Languages \\ Beihang University \\ Beijing, China
}

\begin{abstract}
Grice's theory of conversational implicature has provoked much controversy in recent years. Varieties of plans have been made to advance or even substitute that global pragmatic assumption. Embedded scalar implicature is a case in point which claims that some of the conversational implicatures can be generated at a sub-sentential level. Furthermore, the sub-sentential level conversational implicatures can be projected onto the whole sentence. This paper presents an argument that there is no need to distinguish the sentential level from the sub-sentential level. Gricean theory is adequate to account for the scalar implicatures (especially Q-scalar implicatures) at both levels. Meanwhile, this paper suggests it is the presumptive conditions and the inferential processes rather than the sentential or subsentential levels that should be focused on.
\end{abstract}

Keywords—presumptive; embedded; $Q$-scalar

\section{INTRODUCTION}

Grice regards scalar implicature as conversational implicature that does not arise from conventional meaning of the sentence but an inference of the speaker's intended meaning. In accordance with the neo-Gricean approach, the hearer would choose one scalar alternative as the speaker's communicative intention rather than another, for instance, Mary read some of the books, lies in the quantity and quality maxims: The speaker does not consider that the utterance Mary read all of the books is more informative and truthful, otherwise he should have uttered that. Thus, the implicature of Mary read some of the books are not the case that Mary read all of the books. Undoubtedly, Gricean account of scalar implicatures has been a main stream. However, there is a novel point of view which reasons that John believes that Mary read some of the books has the implicature of John believes that Mary read some but not all of the books. Consequently, the scalar implicature occurs at a subsentential level can be projected onto the sentential level. In general, the Gricean interpretation of scalar implicature is taken as a pragmatic or global view, while the embedded interpretation of scalar implicature is called a conventional or local view.

In this paper, I will introduce the embedded scalar implicature which enjoys tremendous popularity in recent rears first, and then review the debates between the Gricean approach and embedded approach, and then the problems in relation to Gricean implicature will be talked about, and finally my comment and solution to these problems will be given.

\section{EMBEDDED Q-SCALAR IMPLICATURES}

An embedded implicature is a seeming conversational implicature that is engendered locally at the sub-sentential level, typically occurring in a clause that is embedded under a logical operator such as a propositional attitude verb, a conditional and a comparative (Yan Huang 2014: 68). Let us observe the following Q-scalar expressions:

- (1) a. The professor believes that some of his students are hardworking.

b. The professor believes that some but not all of his students are hardworking.

- (2) a. Russell would be less angry if Wittgenstein knocked the door and came in.

b. Russell would be less angry if Wittgenstein knocked the door first and then came in.

- (3) a. I know that he has done most of the housework.

b. I know that he has done most but not whole of the housework.

In example (1), it seems that the implicature created by some can influence the belief clause. Similarly, the implicature of and is locally projected onto the main conditional clause in case (2). Lastly, a factive verb knows is included in instance (3), which contributes to the whole sentential level implicature.

\section{LITERATURE REVIEW}

Yan Huang (2014: 70-3) has briefly reviewed embedded implicatures from the grammatical and pragmatic perspectives. The former approach has two varieties: lexicalist conventionalism and syntax-based/driven conventionalism, while the latter approach contains Gricean globalist and modulation/free enrichment interpretations. In this section, I design to re-examine this topic from theoretical and experimental angles separately.

(i) Theoretical approach. By theoretical approach, I mean the studies that do not contain empirical data. This perspective has two alternations. The one that is in support of and the one that is against embedded implicatures. We shall call them the cons and pros for short. a. The Cons. Recanati (2003: 322-8) writes that there are four possible positions: NN (No-No), YN (Yes-No), NY (No-Yes) and YY (YesYes). He considers that YY (Yes-Yes) is better, which means 
he admits the existence of embedded implicatures. Sauerland (2012: 48) compares the grammatical theory with the $\mathrm{P}+\mathrm{L}$ (pragmatic + lexical) theory, and points out that only grammatical theory predicts intermediate implicatures. After having proposed the or both, sorry/discover, interrogatives puzzles, Gajewski \& Sharvit (2012: 31-57) critically argue that some kind of approach is interwoven with compositional and grammatical mechanisms, thus concluding that grammatical line is necessary to account for the data. $b$. The Pros. Ippolito (2011: 267-78) takes the attitude verb wish which presupposes the counterfactuality of its complement for example to illustrate that grammatical theory of scalar implicatures is problematic. Sauerland (2004: 372) writes that 'My goal in this paper is to show that such a radical break is unwarranted: I will show that the disjunction problem can be solved within Grice's framework,' which indicates his objection to the theory of embedded implicatures. Similar view can be found in Horn (2009: 29), who makes a conclusion that Grice' $s$ theory of scalar implicature retains its strong explanatory force even though the recent critiques of it. Geurts is also an outstanding member who denies the embedded implicature: Most implicatures can be justified within the Gricean framework, and only a few marked cases need to be treated locally in a pragmatic way rather than in a conventional way (Geurts 2009: 51-79). Russell (2006: 361-82) argues that Gricean reasoning can explain the implicatures in certain complex sentences and undesirable implicatures cannot be generated on the one hand, and proves that the computation of grammatical scalar implicature is untenable on the other hand.

Two conclusions can be made from (i): Gricean theory of scalar implicature still plays a vital role and embedded conversational implicature theory is called into question in the theoretical world; the same person may have different opinions on embedded implicatures at different stages, such as Sauerland (2004) \& Sauerland (2012).

(ii) Experimental Approach. In contrast to theoretical approach, experimental approach is employed here to refer to those studies that have data assistance. Analogously, the results of experiment differ in some ways. a. The Cons. Clifton \& Dube (2010: 1-13) gather evidence to suggest that the interpretation of scalar items in embedded context is possible. Chemla (2011: 359-400) provides evidence that subjects sometimes compute embedded scalar implicatures by using a novel version of the truth-value judgment. b. The Pros. Geurts \& Pouscoulous(2009: 1-34) present experimental evidence which disproves conventionalist theory that scalar inferences occur systematically and freely in embedded positions. Chemla (2009: 1-33) offers experimental data that cast doubt on the local/syntactic treatment of scalar implicatures. Tiel (2014: 147-77) experimentally shows how the results of the ones that are on the side of embedded implicuares are affected by typicality.

Comparably, two aspects can be observed from (ii): Although experimental pragmatics gains a tremendous popularity more recently, the application of this method to scalar implicature is relatively few; there are no definite answers to the debates between sentential and sub-sentential arising of scalar implicatures from the perspective of experiments.

In a nutshell, classical conversational implicatures that are engendered at the sentential level still dominate the pragmatic field. Nevertheless, embedded conversational implicatures (specifically Q-scalar implicares) which impose some problems on classical conversational implicatures have attracted an increasing amount of attention and become a topic that cannot be ignored. Let us take a look at what the so-called problems are.

\section{THE PROBLEMS OF GRICEAN APPROACH TO Q- SCALAR IMPLICATURES}

Gricean approach is not able to generate many of the conversational implicatures, which becomes the trigger of embedded implicature. In this section, we will take some Qscalar implicatures for instance to observe the challenge that the Gricean approach has met.

(1) Mr. Darcy believes that Elizabeth has read some books.

It seems as if the scalar implicature that is generated by some can be projected onto the belief clause in (1), as we have already mentioned in Section 2 (1). Some people believe that this cannot be explained by classical Gricean approach.

(2) Mr. Bingley knows that Jane has some of the rooms.

In addition to the implicature Mr. Bingley knows that Jane has some but not all of the rooms, this sentence also has another implicature: Jane does not have all the rooms. But what is the source of the second implicature?

(3) Emma either has a sister or some of the brothers.

Sentence (3) may have the implicature that Emma has neither a sister nor all of the brothers, which entails that Emma does not have a sister. Apparently, the entailment is utterly wrong.

\section{(4) Last month, an earthquake hit Central Nepal.}

According to Gricean interpretation, sentence (4) might implicate that Last month, no earthquake hit Central Nepal, which is a contradictory prediction.

(5) a. I don't LIKE the famous Chinese classical novel Dream of Red Mansions, I LOVE it.

b. I am not HAPPY in reading Dickens' Great Expectations - I am ELATED.

\section{c. Spring in Beijing is WARM than HOT.}

In accordance with a Gricean investigation of (5a), I don't LIKE the famous Chinese classical novel Dream of Red Mansions may give rise to the implicature that I am not in a position to say that I love the famous Chinese classical novel Dream of Red Mansions, which conflicts with the latter part of (5a), namely, I LOVE it. In a similar way, (5b) might imply that I am not in a position to say that I am elated in reading Dickens' Great Expectations, which is a counterpart of I am ELATED. (5c) usually generates a 
Gricean implicature that spring in Beijing is not hot, which accords with than HOT. However, some people show clearly that comparison does not usually contain entailment. To name one example, it would be odd to say that I would rather live in China than Beijing.

\section{A DISCUSSION ABOUT Q-SCALAR IMPLICATURES}

In this section, I will argue that Q-scalar implicatures can be generated on the basis of classical Gricean approach, providing that some presumptive knowledge is added first. Hence, the conventionalist view of conversational implicature is an illusion.

Presumption can be informally defined as a piece of information or a proposition whose truth is taken for granted in the utterance of a sentence. Its main function is to act as a precondition of some sort for the appropriate use of sentence. For instance, I believe her brother is helpful presupposes that She has a brother. Based upon the notion of presupposition, we would propose a relevant but different concept, i.e. 'presumptive condition', to refer to those potential or conceptual or logical possibility occurs in an utterance. I will also lay emphasis on the inferential process of Q-scalar implicatures. All the examples in Section 4 and some additional example will be analyzed on the basis of a classical Gricean appraoch. They are ranked into different categories here: propositional attitude verb, conditional, meta-linguistic negation and comparative.

\section{A. Propositional Attitude Verb}

Mr. Darcy believes that Elizabeth has read some books.

a. There are some books.

b. Elizabeth has read some books.

c. It is not the case that Elizabeth has read all the books.

d. Mr. Darcy believes that it is not the case that Elizabeth has read all the books.

e. Mr. Darcy believes that Elizabeth has read some but not all the books.

In this case, (a) and (b) are presumptive conditions. (c) is inferred from classical Gricean approach. (d) differs from the local approach here. I do not think the implicaure can impress the belief clause. The conversational implicature is inferred first and then the clause Mr. Darcy believes that is added. Ultimately, there comes (e).

Above is a belief report. We can get the same result if a factive verb is used. Please see the following example:

Mr. Bingley knows that Jane ownes some of the rooms.

a. There are some rooms.

b. Jane ownes some of the rooms.

c. It is not the case that Jane ownes all of the rooms.

d. Mr. Bingley knows that it is not the case that Jane ownes all of the rooms. e. Mr. Bingley knows that Jane ownes some but not all of the rooms.

The interpretation here is easy: (a) and (b) are considered as presumptive conditions; (c) is the Gricean conversational implicature; a clause is attached to this Gricean implicature in (d); and (e) is the conversational implicature of the whole sentence.

\section{B. Conditional}

Emma either has a sister or some of the brothers.

a. Emma has a sister.

b. Emma has some of the brothers.

c. Emma either has a sister or some of the brothers.

d. It is not the case that Emma either has a sister or all of the brothers.

e. Emma either has no sister or some but not all of the brothers.

f. Emma either has a sister or some but not all of the brothers.

Here, (a) and (b) are the possible presumptive conditions. (c) is the composition of (a) and (b), which is the same as the original sentence Emma either has a sister or some of the brothers. (d) and (e) are derived from an Gricean account. Finally, (f) is adopted instead of (e), for (e) contradicts with the possible presumptive condition (a). It is inappropriate to exclude (a) given that it is also one of the conceptual possible presumptive conditions.

This applies to indefinites too. See the sentence below for example:

Last month, an earthquake hit Central Nepal.

a. There is a country called Central Nepal.

b. Last month, an earthquake hit Central Nepal.

c. It is not the case that last month no earthquake hit Central Nepal.

\section{d. Last month, an earthquake hit Central Nepal.}

Among the conditions, (a) is the presumptive one. (b) is the presumptive sentence that is (a) based. (c) is a Gricean generation. (d) is the overall scalar implicature. One may find that (b) and (d) are no difference. That view is totally wrong because of the fact that (b) is regarded as a presumptive condition and (d) is the outcome.

\section{Meta-linguistic Negation}

Meta-linguistic negation is a device for rejecting a previous utterance on any grounds whatever including its morphosyntactic form, its phonetic realization, and its style or register (Yan Huang 2014: 54). I don't LIKE the famous Chinese classical novel Dream of Red Mansions, I LOVE it is one case in point whose implicature can be illustrated as follows: 
a. There is a famous Chinese classical novel named Dream of Red Mansions.

b. It is not the case that I love the famous Chinese classical novel Dream of Red Mansions.

c. I don't love the famous Chinese classical novel Dream of Red Mansions.

(a) is the presumptive condition. (b) and (c) are the preliminary Gricean conversational implicature. Pay attention to the word preliminary which means (b) and (c) are not the ultimate Gricean conversational implicature. Meta-linguistic negation is an intriguing feature of Q-scalar implicature which is distinguished from others by its morphosyntactic form, phonetic realization, and style or register. Here LIKE is used, thus indicating that the true conversational implicature is the opposite. Hence, the implicature that I LOVE the famous Chinese classical novel Dream of Red Mansions is the final answer.

It is the same story of the following instance:

I am not HAPPY in reading Dickens' Great Expectations - I am ELATED.

a. Dickens has written a novel named Great Expectations.

b. It is not the case that I am elated in reading Dickens' Great Expectations.

c. I am not elated in reading Dickens' Great Expectations.

(a) is the presumptive condition. (b) and (c) are the preliminary Gricean conversational implicature. Again here HAPPY is used, which manifests that the final conversational implicature is I am ELATED in reading Dickens' Great Expectations.

\section{Comparative}

It has dissolved the problem of a special kind of comparative, in other words, meta-linguistic negation. We will move onto the common comparative here. Please look at the coming examples:

\section{Spring in Beijing is WARM than HOT.}

a. There is a city called Beijing whose spring is warm.

b. Spring in Beijing is not hot.

c. Spring in Being is warm but not hot.

d. Spring in Being is WARM than HOT.

(a) is the presumptive meaning. (b) and (c) are Griceanbased implicatures. The distinction between common comparative and meta-linguistic negation is in (d). In common comparative, WARM implicates not HOT, but it is not the case in meta-linguistic negation. Below is another instance:

It is better to eat FEW than ALL of the peaches.

a. There are peaches.

b. It is better to eat few peaches.

c. It is better to eat few but not all of the peaches. d. It is better to eat FEW than ALL of the peaches.

(a) is the presumptive condition. (b) is part of the original sentence which is also related to the presumptive condition. (c) is a Gricean conversational analysis. (d) is a possible implicature of (c).

\section{CONCLUSION}

In the light of the classical Gricean conversational approach, this paper takes Q-scalar implicature for example to solve the puzzles between globalism and localism: The problem of the Q-scalar implicatures and the solution are of primary. Embedded/local implicature is claimed to be embedded under propositional attitude verb, conditional, comparative, etc. For a better interpretation, this paper has brought 'presumptive condition' in, which is a prerequisite for classical Gricean inference. The conclusion is that it is not necessary to divide the source of implicatures into two parts: the sentential level and the sub-sentential level. By adding the presumptive conditions to Gricean account, the scalar implicatures (especially Q-scalar implicatures) at both levels can be generated. Admittedly, there are some limitations in this paper: The linguistic data are few; factive verbs are grouped into propositional attitude verbs, and indefinites ascribe to conditional for a convenient discussion; there may be some cases where presumptive condition is not needed at all. Nevertheless, this paper is an attempt to interpret Q-scalar implicatures from a presumptive scope, and therefore is titled Presumptive Q-scalar Implicatures.

\section{REFERENCES}

[1] Chemla, E., 2009, 'Universal implicatures and free choice effects experimental data'. Semantics \& Pragmatics2, 1-33.

[2] Chemla, E., 2011, 'Experimental evidence for embedded scalar implicatures'. Journal of Semantics28, 359-400.

[3] Clifton, C. \& C. Dube, 2010, 'Embedded implicatures observed: a comment on Geurts and Pouscoulous (2009)'. Semantics \& Pragmatics3, 1-13.

[4] Gajewski, E. \& Y. Sharvit, 2012, 'In defense of the grammatical approach to local implicatures'. Nat Lang Semantics20, 31-57.

[5] Geurts, B., 2009, 'Scalar implicature and local pragmatics'. Mind \& Language24, 51-79.

[6] Geurts, B., Quantity Implicatures. New York: Cambridge University Press. 2010.

[7] Geurts, B. \& N. Pouscoulous, 2009, 'Embedded implicatures?!?*' Semantics \& Pragmatics2, 1-34.

[8] Horn, L., 2009, 'WJ-40: implicature, truth, and meaning'. International Review of Pragmatics1, 3-34.

[9] Ippolito, M., 2011, 'A note on embedded implicatures and counterfactual presuppositions'. Journal of Semantics28, 267-78.

[10] Recanati, F., 2003, 'Embedded implicatures'. Language and Philosophical Linguistics17, 299-328.

[11] Russell, B., 2006, 'Against grammatical computation of scalar implicatures'. Journal of Semantics23, 361-82.

[12] Sauerland, U., 2004, 'Scalar implicatures in complex sentences'. Linguistics and Philosophy27, 367-91.

[13] Sauerland, U., 2012, 'The computation of scalar implicatures pragmatic, lexical or grammatical?'. Language and Linguistics Compass6, 36-49.

[14] Tiel, B., 2014, 'Embedded implicatures and typicality'. Journal of Semantics31, 147-77. 
[15] Huang, Yan, Pragmatics (2nd edition). Oxford: Oxford University Press, 2014. 